\title{
HMO PARTICIPATION IN MEDICARE+CHOICE
}

\author{
JOHN CAWLEY \\ Department of Policy Analysis and Management \\ Cornell University \\ Ithaca, NY 14853 \\ jhc38@cornell.edu \\ Michael Chernew \\ Department of Health Management and Policy \\ University of Michigan \\ Ann Arbor, MI 48109-2029 \\ mchernew@umich.edu \\ Catherine McLaughlin \\ Department of Health Management and Policy \\ University of Michigan \\ Ann Arbor, MI 48109-2029 \\ cmcl@umich.edu
}

In recent years, many health maintenance organizations (HMOs) have exited Medicare + Choice $(M+C)$, the program that provides a managed-care option to Medicare. This paper answers the following questions: How does the equilibrium number of HMOs participating in county $M+C$ markets vary with the capitation payment they are offered? How large a payment is required at the margin to ensure that various percentages of county markets have a $M+C H M O$, or to ensure that various percentages of Medicare beneficiaries have the choice of a $M+C$ plan in their county of residence? The strategy for identifying the effect of government payment on HMO participation relies on a natural experiment; in 1997, Congress divorced $M+C$ payments to HMOs from changes in underlying costs. The results in this paper suggest that the Centers for Medicare \& Medicaid Services (CMS) has consistently underestimated the payment necessary to support HMOs in rural, sparsely populated areas. We also find that it would require a large incremental payment to support HMOs in $M+C$ for the final $10 \%$ of counties or final $10 \%$ of Medicare beneficiaries.

We thank Scott Adams, David Colby, Julie Cullen, Rachel Dunifon, Hanns Kuttner, Will Manning, Katie Merrell, Daniel Spulber, two anonymous referees, and seminar and conference participants for their helpful comments. We thank Phil DeCicca for research assistance and Justine Lynge for editorial assistance.

(C) 2005 Blackwell Publishing, 350 Main Street, Malden, MA 02148, USA, and 9600 Garsington Road, Oxford OX4 2DQ, UK.

Journal of Economics \& Management Strategy, Volume 14, Number 3, Fall 2005, 543-574 


\section{INTRODUCTION}

Faced with rapidly rising Medicare costs, Congress in 1982 directed the Centers for Medicare \& Medicaid Services $(\mathrm{CMS})^{1}$ to contract with health maintenance organizations (HMOs) to provide managed care to Medicare beneficiaries. Under this program, now titled Medicare+Choice $(\mathrm{M}+\mathrm{C})^{2}$, HMOs furnish all Medicare-covered services in exchange for a per-capita prospective payment. ${ }^{3}$

This paper seeks to answer the following questions concerning the $\mathrm{M}+\mathrm{C}$ program. How does the equilibrium number of $\mathrm{HMOs}$ participating in county $\mathrm{M}+\mathrm{C}$ markets vary with the CMS capitation payment they are offered? ${ }^{4}$ How does the percent of counties with at least one $\mathrm{M}+\mathrm{C}$ HMO vary with the CMS payment rate? How large a CMS payment is required to ensure that various percentages of Medicare beneficiaries have the choice of a $\mathrm{M}+\mathrm{C}$ plan in their county of residence?

Our strategy for identifying the effect of CMS payment on HMO participation is to observe how the number of participating HMOs varies over counties and time in response to changes in CMS payment while controlling for estimated costs. Variation in payment comes from a natural experiment; in 1997, Congress divorced M+C payments to HMOs from changes in underlying costs.

The number of $\mathrm{HMOs}$ participating in $\mathrm{M}+\mathrm{C}$ markets is important for several reasons. In the HMO market there is considerable product differentiation on many dimensions. The number of participating HMOs is a measure of the extent of choice enjoyed by beneficiaries. The participation of a single $\mathrm{HMO}$ in a $\mathrm{M}+\mathrm{C}$ market offers Medicare beneficiaries in that market an alternative to fee-for-service care. The participation of several HMOs in a market results in greater competition for enrollment, which has the salutary effect of increasing benefits and/or lowering costs for managed care enrollees. ${ }^{5}$

1. In 2001, the Health Care Financing Administration was renamed the Centers for Medicare \& Medicaid Services (CMS). For the sake of consistency, the agency is referred to as CMS throughout this paper.

2. The program we study has had several names during its history. It was not titled Medicare+Choice until the Balanced Budget Act of 1997, and it was renamed Medicare Advantage by the Medicare Prescription Drug, Improvement, and Modernization Act of 2003. For the sake of consistency we shall refer to the program by its name during most of the period we examine: Medicare+Choice.

3. In the past, CMS also wrote cost contracts with HMOs under which HMOs cared for Medicare beneficiaries on a fee-for-service basis. This paper is concerned exclusively with Medicare risk contracts.

4. Distinct from tracing a supply curve, this paper estimates the number of suppliers in the market as a function of the price, controlling for estimated costs.

5. Physician Payment Review Commission (1996), GAO Report 97-113 (1997). Pizer and Frakt (2002) study M+C data from 1999-2001 and conclude that competition between plans (measured by the Herfindahl index) is strongly correlated with lower premiums and greater plan benefits. 
Consistent with the fact that the number of $\mathrm{M}+\mathrm{C}$ plans in a market is correlated with the generosity of benefits offered to enrollees, the probability that an individual involuntarily disenrolled from an $\mathrm{M}+\mathrm{C}$ $\mathrm{HMO}$ will subsequently enroll in another $\mathrm{M}+\mathrm{C} \mathrm{HMO}$ is positively correlated with the number of $\mathrm{M}+\mathrm{C}$ HMOs remaining in the market (Booske et al., 2002; Laschober et al., 1999). Among those with a choice of five or more $\mathrm{M}+\mathrm{C}$ HMOs, $89 \%$ enrolled in another $\mathrm{M}+\mathrm{C} \mathrm{HMO}$, compared to $54 \%$ of those with only one $\mathrm{M}+\mathrm{C} \mathrm{HMO}$ available to join. ${ }^{6}$ A greater number of $\mathrm{M}+\mathrm{C}$ HMOs in a market may cushion the adverse consequences of involuntary disenrollment.

Beneficiaries and policymakers have also recognized the importance of the number of plans serving a market. A recent poll indicates that four out of five senior citizens believe that it is important for seniors to have a choice of health plans (PR Newswire, 2003). Moreover, President Bush has called for strengthening the $\mathrm{M}+\mathrm{C}$ program to provide greater choice of plans for senior citizens (PR Newswire, 2002).

Nevertheless, we recognize that other outcomes may be interesting as well and offer two extensions. One examines the impact of CMS payment on the likelihood that the county market is served by at least one $\mathrm{HMO}$ and the other examines the impact of payment on the HMO penetration rate into Medicare in that market.

Under the current law, those eligible for Medicare Part A (Hospital Insurance) and enrolled in Medicare Part B (Supplementary Medical Insurance) may enroll in a managed care plan, if available. ${ }^{7}$ Traditional fee-for-service Medicare is still available to all Medicare beneficiaries. Figure 1 depicts the number of Medicare managed care enrollees from 1985 to 2001, a period during which enrollment grew from 440,000 in 1985 to a peak of 6.35 million in 1999 before falling to 5.6 million in $2001 .{ }^{8}$ In 2001, $15 \%$ of all Medicare beneficiaries chose M+C. ${ }^{9}$

The continuous growth in enrollment during 1985-1999 masks considerable change in the number of $\mathrm{HMO}$ plans participating in $\mathrm{M}+\mathrm{C}$. Figure 2 shows that many plans exited $\mathrm{M}+\mathrm{C}$ in the late 1980s, but the number of participating plans rose considerably during the early- and mid-1990s. Between 1998 and 2001, however, the number of participating plans fell from 346 to 174 .

As a result of the reduced participation of HMOs, many Medicare beneficiaries have been involuntarily disenrolled from the program. The

6. Laschober et al. (1999).

7. Medicare beneficiaries may enroll only in those HMOs with a risk contract from CMS to serve the beneficiary's county of residence. Medicare beneficiaries suffering from end-stage renal diseases are not eligible for Medicare managed care.

8. HCFA Medicare Managed Care Contract Reports are the source of the data shown in Figures 1 and 2.

9. HCFA Medicare Managed Care January Contract Report (2001). 


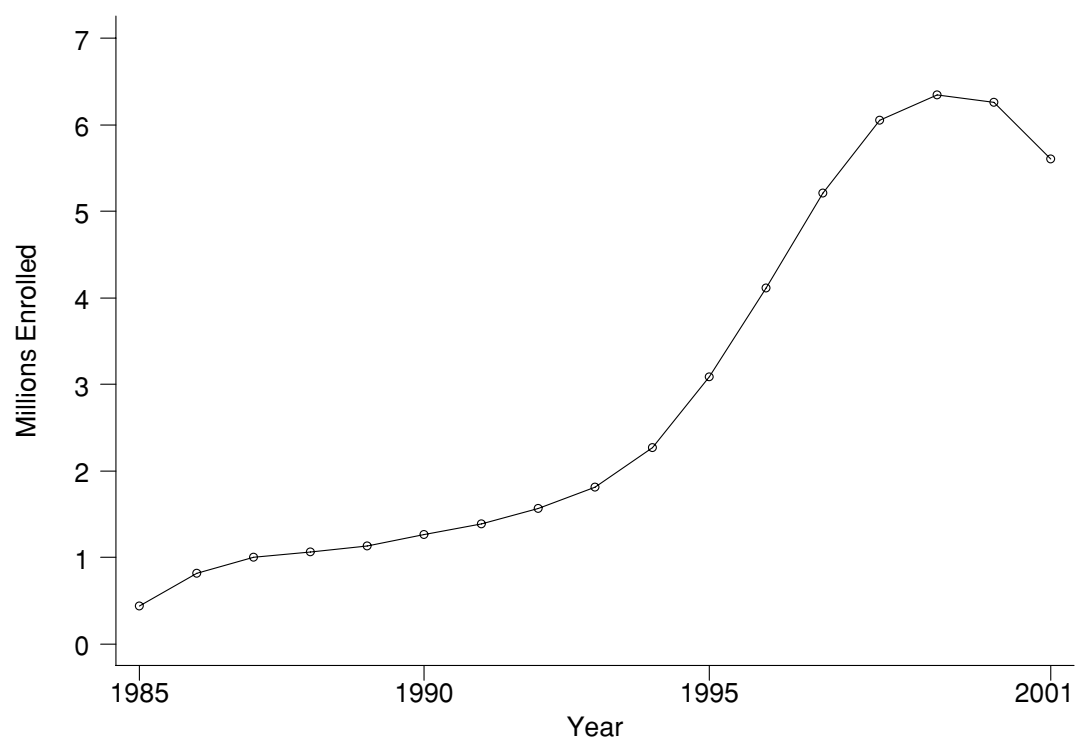

FIGURE 1. MEDICARE+CHOICE ENROLLMENT

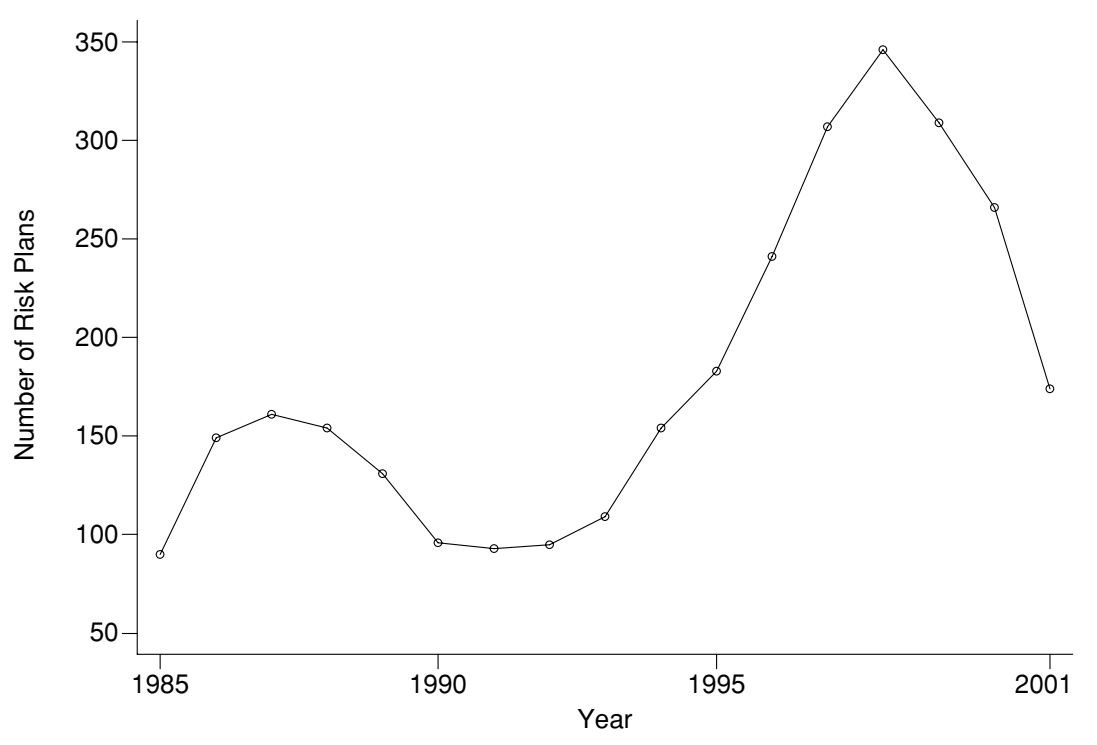

FIGURE 2. NUMBER OF MEDICARE+CHOICE PLANS 
number of Medicare beneficiaries involuntarily disenrolled from $\mathrm{M}+\mathrm{C}$ plans at the close of recent years totaled 407,000 in 1998, 327,000 in 1999, 934,000 in 2000, and 536,000 in 2001. ${ }^{10}$

Our results suggest that CMS has consistently underestimated the payment necessary to support HMOs in rural, sparsely populated areas. We also find that it would require a large incremental payment to support HMOs in $\mathrm{M}+\mathrm{C}$ for the final $10 \%$ of counties or final $10 \%$ of Medicare beneficiaries.

This paper does not take a position how many $\mathrm{M}+\mathrm{C}$ HMOs should be supported in each county and does not attempt to quantify the benefits of diversity. Ultimately, policy makers may well decide the benefits are not worth the cost. Moreover, this paper does not estimate how much needs to be paid in the future; this paper is only able to examine the relationship between payment and participation retrospectively. A prediction about payments necessary to support given numbers of HMOs in the future depends on information about changing costs in local health care markets that is not yet available.

Three studies have modeled the decisions of individual HMOs to participate in the M+C market (Adamache and Rossiter, 1986; Porell and Wallack, 1990; and Abraham et al. 2000). Each of these studies used HMO-level data, which entails two complicated problems, neither of which is addressed by the three referenced studies.

The first problem is that, in counties that have noncompetitive $\mathrm{M}+\mathrm{C}$ markets, the entry decision of each firm is a function of the entry decisions of all potential participants in that market. Complicating the problem, some potential participants are not observed because they chose not to enter.

The second problem inherent in the use of HMO-level data to study this problem is the likelihood of multiple equilibria. For example, a county may be able to support two HMOs in its $\mathrm{M}+\mathrm{C}$ market, but it may be largely random which two HMOs participate. Bresnahan and Reiss (1991a) show that multiple equilibria occur in simultaneous-move models under very general conditions.

In this paper, we study the aggregate number of HMOs participating at the county level. This avoids the problems of simultaneity and multiple equilibria because we are concerned only with the number of firms that can be supported in the county, not the identities of the individual HMOs.

We also relate to a more recent literature on $\mathrm{HMO}$ participation in the $\mathrm{M}+\mathrm{C}$ program. Pai and Clement (1999) study the determinants of 
whether an HMO signs a risk contract with CMS to participate in $\mathrm{M}+\mathrm{C}$. Penrod, McBride, and Mueller (2001) study the relationship between CMS payment and plan enrollment in 1996, prior to the payment reform created by the BBA of 1997. Liu (2002) studies the difference in $\mathrm{M}+\mathrm{C}$ activity between urban and rural areas.

The outline of this paper is as follows. Section 1 describes the natural experiment that provides much of our identification. Section 2 outlines our method for examining the relationship between CMS payment rates and the extent of HMO participation. Section 3 describes the data used in this study, Section 4 presents the results of the empirical work, and Section 5 presents extensions.

\section{HMO PAYMENT REFORM}

Much of our identification of the effect of payment holding constant costs comes from a natural experiment. Congress, in the Balanced Budget Act (BBA) of 1997, changed the CMS formula for setting payment levels effective 1998.

During the early part of our sample (1993-1997), county CMS payments were set according to the 1982 Tax Equity and Fiscal Responsibility Act (TEFRA). Under TEFRA, HMOs were paid 95\% of the projected average fee-for-service costs of Medicare beneficiaries in that county, multiplied by a risk-adjustment factor based on the enrollee's age, sex, Medicaid eligibility, institutional status, and working status. HMOs were paid only $95 \%$ of projected local costs because CMS expected that HMOs could save $5 \%$ by operating more efficiently and with fewer unnecessary procedures than fee-for-service providers. TEFRA allowed Medicare HMOs to earn a rate of profit equal to that earned in their nonMedicare business. ${ }^{11}$ Subject to CMS approval, HMOs were allowed to charge a premium to enrollees in exchange for services not covered by Medicare.

The TEFRA payment formula was criticized for overpaying HMOs. Despite the strategy of paying HMOs $95 \%$ of projected average fee-for-service costs, several studies concur that it cost CMS more to enroll beneficiaries in $\mathrm{M}+\mathrm{C}$ than if they had remained in fee-for-service Medicare. $^{12}$ The reason is that enrollees in $\mathrm{M}+\mathrm{C}$ have proven to be systematically healthier than fee-for-service Medicare beneficiaries and as a result the medical expenses of the $\mathrm{M}+\mathrm{C}$ enrollees were far lower than $95 \%$ of average fee-for-service costs.

11. If the expected rate of Medicare profit exceeds that of non-Medicare business, the $\mathrm{HMO}$ must either return the excess to CMS, provide additional benefits, or reduce its co-payments and deductibles.

12. GAO Report 00-161 (2000). Favorable selection occurred even though HMOs are prohibited by law from selecting enrollees on the basis of health status. 
The TEFRA payment formula was also criticized for creating disparities in payments across counties; in particular, few HMOs entered rural counties. It was also argued that tying managed care payments to local fee-for-service charges rewarded counties that were inefficient at providing fee-for-service care.

Concerned about the rising cost of caring for Medicare beneficiaries, Congress passed the BBA of 1997, which changed the formula determining the amount HMOs are paid under the program. ${ }^{13}$ Since 1998, CMS pays HMOs the greatest of the following three rates: ${ }^{14}$

1. A blend of a national rate and an area-specific rate. The blend is intended to reduce the variation in payments across counties by increasing the lowest rates and decreasing the highest rates. If total projected payments exceed a budget limit, the blended rate is reduced. The budget limits have typically been binding, forcing reductions so great that only in the year 2000 did any county receive the blended payment.

2. A national minimum payment, adjusted annually, intended to increase the rates in historically lower-rate counties where $\mathrm{M}+\mathrm{C}$ plans generally have not been offered.

3. A minimum increase over the previous year's payment, which is intended to somewhat protect high payment areas. For 1998, 1999, 2000, and January and February of 2001, the minimum increase over the previous year's payment was 2\%. For March-December of 2001 the minimum increase was $3 \%$.

The BBA also affected HMO profits by increasing their administrative burdens and charging them user fees (which amounted to $\$ 95$ million in both 1998 and 1999), the proceeds of which are used to inform Medicare beneficiaries about their managed-care options. ${ }^{15}$

There is one final component of HMO payment in this program. The Balanced Budget Refinement Act of 1999 mandates that CMS, starting in the year 2000, pay bonuses of 5\% the first year, and 3\% the second year, to HMOs that offer $\mathrm{M}+\mathrm{C}$ in previously unserved counties. ${ }^{16}$

13. Some provisions of the BBA were amended by the Balanced Budget Refinement Act of 1999 and the Medicare, Medicaid, and SCHIP Benefits Improvement and Protection Act of 2000.

14. In addition, the BBA requires CMS to adjust payments by the health status of plan enrollees. The risk adjustment will be phased in; payments in 2001 are $10 \%$ risk adjusted and $90 \%$ adjusted only for demographic factors. The full amount of the payment will be risk-adjusted by 2004 . The BBA also requires that graduate medical education reimbursements be phased out of the county payments.

15. The BBA also dropped the requirement that plan service areas had to consist of contiguous counties.

16. The bonus is paid to the first HMO to enter a previously unserved county, but if several HMOs enter on the same date they each receive the bonus. 


\section{Methods}

The relationship between exogenously set payment rates and the number of firms in the market depends on many factors. Important factors include the nature of competition in the industry, the shape of the cost curves, information, and the extent to which quality competition is possible. Moreover, the number of firms in the market is determined by a dynamic process. Thus strategic concerns and expectations regarding factors such as whether firms interpret shocks to demand as permanent or transitory are also important. Models could be constructed which have the property that the number of firms rises with an exogenously set payment rate and others could be constructed in which the surplus created by rising payment rates is dissipated in ways other than by increased entry into the market. Multiple equilibria are possible (Pakes and McGuire, 1994; Sutton, 1991). Nevertheless, it is commonly true (but not always the case) that economic models predict that an increase in an exogenously set price leads to a greater number of firms in the market. We are not interested in testing any particular model, but instead desire to measure the magnitude of the relationship between price and number of firms.

Our empirical model follows the approach outlined in Bresnahan and Reiss, (1991b); if N HMOs are active in a market, we assume that the Nth HMO earns zero economic profits when

$\prod_{N}(P)=\left[P-A V C\left(q_{N}, W\right)\right] \frac{1}{N} d(Z) S-r F=0$,

where $P$ is the CMS payment, $A V C(\bullet)$ is the average variable cost function of the HMO, $d(\bullet)$ is the probability that a Medicare beneficiary enrolls in Medicare managed care, $Z$ is a vector of variables that affect the probability of enrollment, $S$ is the number of Medicare beneficiaries, $r$ is the interest rate, and $F$ is the fixed cost of entry. $W$ is a vector of variables affecting costs, and $q$ is the number of Medicare managed-care enrollees in the HMO (i.e. $q_{N}=\frac{1}{N} d(Z) S$ ).

We assume that profit has an additively separable unobserved component, represented by an error term.

$\prod_{N}=\prod_{N}+\varepsilon$

It is assumed that the error term is normally distributed, uniform within markets, independent across markets, and independent of the regressors. These assumptions permit the use of the ordered probit to estimate entry thresholds. The dependent variable is the number of HMOs participating in $\mathrm{M}+\mathrm{C}$ in a county. 
A county will have $N$ active HMOs when the $N$ th HMO to participate earns non-negative profits but an additional entrant would earn negative profits.

$\prod_{N} \geq 0$ and $\prod_{N+1}<0$

The probability that $N$ HMOs participate in the market equals

$\operatorname{Pr}\left(\prod_{N} \geq 0\right.$ and $\left.\prod_{N+1}<0\right)=\Phi\left(\prod_{N}^{-}\right)-\Phi\left(\prod_{N+1}^{-}\right)$,

where $\Phi(\cdot)$ is the cumulative standard normal distribution function.

We estimate the latent profit function using a reduced form approach. Cameron and Trivedi (1998) conclude that when the data generating process is a continuous latent variable (in our case unobserved profits), an ordered model should be used in place of a count data regression model. Accordingly, we estimate the model using an ordered probit regression, in which the number of participating HMOs in a given county in a given year is a function of payment and the factors that affect variable costs, market size, the probability of enrollment, and fixed costs.

The ordered probit specification provides a convenient way to relate the number of firms in the market to price, costs, and variables related to market size. It is not designed to differentiate between any of the many models that might give rise to the relationship between price and number of firms in the market.

Ordered probit regression will provide us with threshold values of CMS payments for HMO participation. If $\beta_{P}$ represents the coefficient on CMS payment, $\beta$ represents the vector of all other coefficients, and $X$ represents the set of regressors other than CMS payment, then the minimum CMS payment $P$ needed to support the participation of $N$

HMOs is: $P_{N}=\frac{\lambda_{N}-X \beta}{\beta_{P}}$,

where $\lambda_{N}$ is the cutoff in the ordered probit regression associated with $N$ HMOs. ${ }^{17}$ We predict that a higher CMS payment, controlling for observable factors that affect costs, will be associated with the participation of a greater number of HMOs. The payment thresholds we calculate are based on current payment and observed market characteristics; to the extent that unobserved factors, such as firm expectations about future

17. If the dependent variable in an ordered probit regression has $M$ categories, the cutoffs represent fitted values above which the model predicts that the dependent variable will equal $m$ for $m=1, \ldots, M$. 
strategic interactions with rival HMOs, influence the HMO participation decision, our estimates of payment thresholds will be biased.

\section{DATA}

In this section, we define HMO participation in county markets and explain how we control for each component of the profit function introduced in the previous section. The data used in this paper come from two sources. The CMS is the source for data on $\mathrm{M}+\mathrm{C}$ enrollment, Medicare managed care contracts with HMOs, CMS payments by county, and input price indices. Plan-county data are aggregated to the HMO level and HMO-level data are aggregated to the county level. ${ }^{18}$ The second major source of data for this paper is the Area Resource File (ARF), which provides medical and demographic data at the county level. ${ }^{19}$

The sample contains every county in the contiguous 48 United States plus Washington D.C. for each year 1993-2001. Counties represent distinct markets for Medicare managed care. A market has traditionally been defined as a region in which a single price prevails for a homogenous good ${ }^{20}$ and CMS sets $\mathrm{M}+\mathrm{C}$ payments on a county-by-county basis. Furthermore, exit and entry occur at the county level; CMS requires separate contracts from HMOs for each county in which they wish to offer Medicare managed care.

The dependent variable used in this paper is the number of HMOs participating in a county in a given year; it is top-coded at six or more; Table I lists the number of counties with a given number of HMOs participating in $\mathrm{M}+\mathrm{C}$ by year. ${ }^{21}$ For the purposes of this study, a risk plan is defined as participating in a county $\mathrm{M}+\mathrm{C}$ market if CMS market penetration files indicate that the plan has enrolled at least $0.5 \%$ of the county's Medicare-eligible residents. ${ }^{22}$

18. A plan is a uniform set of benefits and premiums. Each HMO may offer multiple plans. In our data we find only 37 counties in which a single HMO offers two plans.

19. The Area Resource File (ARF) is a compilation of data from a variety of sources. Unless otherwise noted, the original source of data taken from the ARF is the 1990 Census of Population and Housing.

20. See, for example, Marshall (1920).

21. We top-code the dependent variable because it can be difficult to estimate an ordered probit for values of the dependent variable that appear rarely in the data.

22. The enrollment data used to determine HMO participation is that for December for 1993-1997 and 2000, October for 1998-1999, and March in 2001. December reports are not used for 1998 and 1999 because the figures listed in those December reports are actually from the following January. We exclude plans that have enrolled less than $0.5 \%$ of eligible residents because plans with such low county enrollment may not actually be operating in the county; CMS market penetration files list enrollees by their county of residence instead of the county in which they have enrolled in an $\mathrm{HMO}$, and as a result there are many plan enrollees found in counties where the plan does not have a contract to operate. 
TABLE I.

NUMBER OF COUNTIES WITH A GIVEN NUMBER OF HMOS PARTICIPATING IN MEDICARE+CHOICE, BY YEAR

\begin{tabular}{|c|c|c|c|c|c|c|c|c|c|}
\hline \multirow{2}{*}{$\begin{array}{l}\text { Number of } \\
\text { HMOs in County } \\
\text { Participating in } \\
\text { Medicare+Choice }\end{array}$} & \multicolumn{9}{|c|}{ Year } \\
\hline & 1993 & 1994 & 1995 & 1996 & 1997 & 1998 & 1999 & 2000 & 2001 \\
\hline 0 & 2,816 & 2,728 & 2,569 & 2,401 & 2,289 & 2,230 & 2,210 & 2,273 & 2,415 \\
\hline 1 & 166 & 202 & 281 & 309 & 317 & 329 & 387 & 366 & 336 \\
\hline 2 & 55 & 81 & 114 & 155 & 188 & 205 & 199 & 189 & 183 \\
\hline 3 & 21 & 30 & 56 & 101 & 105 & 126 & 126 & 116 & 88 \\
\hline 4 & 4 & 22 & 28 & 48 & 84 & 80 & 74 & 70 & 23 \\
\hline 5 & 7 & 3 & 14 & 43 & 51 & 57 & 34 & 27 & 14 \\
\hline $6-10$ & 5 & 8 & 12 & 17 & 40 & 47 & 44 & 34 & 15 \\
\hline $\begin{array}{c}\text { Total Number } \\
\text { of Counties }\end{array}$ & 3,074 & 3,074 & 3,074 & 3,074 & 3,074 & 3,074 & 3,074 & 3,074 & 3,074 \\
\hline
\end{tabular}

Data: CMS Medicare managed care market penetration files, 1993-2001.

TABLE II.

PERCENT OF ALL MEdicARE Beneficiaries LiVing in COUNTIES With A CERTAIN NuMBER OF HMOS PARTICIPATING IN MEdicARE+CHOICE

\begin{tabular}{lrrrrrrrrr}
\hline $\begin{array}{l}\text { Number of HMOs } \\
\text { Participating in } \\
\text { Medicare+Choice }\end{array}$ & \multicolumn{7}{c}{ Year } \\
\cline { 2 - 10 } & 1993 & 1994 & 1995 & 1996 & 1997 & 1998 & 1999 & 2000 & 2001 \\
\hline 0 & 61.84 & 55.96 & 44.47 & 35.25 & 31.73 & 30.23 & 29.79 & 31.35 & 35.60 \\
1 & 15.42 & 14.25 & 16.42 & 13.87 & 10.44 & 9.46 & 10.53 & 11.39 & 14.38 \\
2 & 10.09 & 11.50 & 13.41 & 12.33 & 11.09 & 10.68 & 10.17 & 11.46 & 16.32 \\
3 & 3.77 & 5.90 & 8.25 & 13.28 & 11.84 & 12.10 & 14.36 & 14.45 & 13.51 \\
4 & 2.08 & 5.42 & 6.45 & 8.15 & 11.48 & 10.86 & 12.36 & 10.30 & 5.43 \\
5 & 2.21 & 0.61 & 3.06 & 7.69 & 8.75 & 10.63 & 5.82 & 5.41 & 3.47 \\
$6-10$ & 4.59 & 6.35 & 7.94 & 9.44 & 14.67 & 16.04 & 16.97 & 15.63 & 11.28 \\
\hline
\end{tabular}

Table I indicates that the number of counties with zero HMOs participating in M+C fell every year from 1993-1999, but recently has risen each year 1999-2001. In 2001, 78.6\% of counties had zero HMOs participating in $\mathrm{M}+\mathrm{C}$.

Table II presents the percent of all Medicare beneficiaries living in counties with a given number of HMOs participating in this program in each year. Table II shows a similar trend to that observed in Table I; the percent of Medicare beneficiaries living in counties with no HMOs participating in M+C fell from 1993-1999 but then rose in 1999-2001. 
TABLE III.
PERcent of Counties With at least One HMO Active IN MEDICARE+CHOICE, BY QUINTILE OF MEDICARE BENEFICIARIES IN 1990

\begin{tabular}{lrrrrr}
\hline & \multicolumn{5}{c}{ Quintile of Medicare Beneficiaries in 1990} \\
\cline { 2 - 6 } Year & \multicolumn{1}{c}{1} & 2 & \multicolumn{1}{c}{3} & 4 & 5 \\
\hline 1993 & 4.7 & 2.4 & 3.9 & 7.5 & 23.5 \\
1994 & 5.4 & 3.6 & 6.0 & 10.7 & 30.6 \\
1995 & 7.6 & 4.9 & 9.8 & 15.3 & 44.6 \\
1996 & 9.8 & 7.2 & 13.0 & 22.4 & 57.2 \\
1997 & 9.9 & 9.3 & 17.1 & 27.8 & 63.7 \\
1998 & 10.9 & 10.4 & 18.9 & 31.4 & 65.8 \\
1999 & 7.6 & 12.8 & 20.3 & 33.3 & 66.4 \\
2000 & 6.5 & 12.4 & 17.1 & 31.1 & 63.4 \\
2001 & 4.2 & 9.4 & 13.8 & 22.6 & 57.2 \\
\hline Number of Counties & 615 & 615 & 615 & 615 & 614 \\
\hline Minimum Number of Medicare & 14 & 1,482 & 2,783 & 4,714 & 9,718 \\
$\quad$ Beneficiaries in Quintile & & & & & \\
Maximum Number of Medicare & 1,479 & 2,781 & 4,708 & 9,680 & 877,581 \\
$\quad$ Beneficiaries in Quintile & & & & & \\
\hline
\end{tabular}

Data: CMS market penetration files, 1993-2001, and area resource file.

Table II also indicates that in 2001, $11.3 \%$ of beneficiaries lived in counties with six or more HMOs active in $\mathrm{M}+\mathrm{C}$.

Although $78.6 \%$ of counties in 2001 had no HMO participating in $\mathrm{M}+\mathrm{C}$, only $35.6 \%$ of all Medicare beneficiaries lived in those counties. This is due to the fact that HMO participation in this program is strongly correlated with the number of Medicare beneficiaries residing in a county. Table III lists the percent of counties with at least one HMO participating in $\mathrm{M}+\mathrm{C}$, by the quintile of its population of Medicare beneficiaries. The table shows that counties in the fifth (most populous) quintile are several times more likely to have a participating HMO than are counties in the first quintile (least populous). The positive correlation between the size of the Medicare population and the probability that an HMO participates in M+C was stronger in 2001 than in 1993.

Figure 3 depicts the number of HMOs participating in $\mathrm{M}+\mathrm{C}$ by county of the US in the year 2001. The map confirms the pattern observed in Table III that populous counties are more likely to support HMO participation in $\mathrm{M}+\mathrm{C}$.

\subsection{VARIABLE DEFINITIONS}

To recap, the profit function for all HMOs in a market, and thus the number of HMOs participating in a county is posited to be a function 


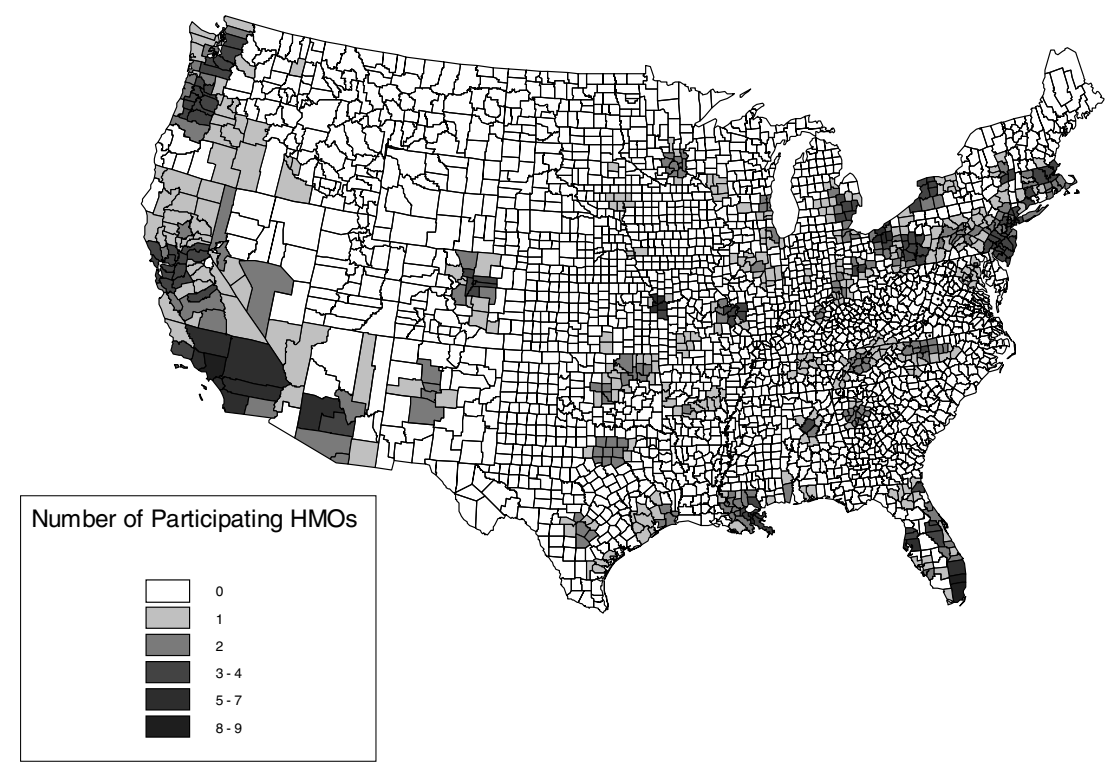

FIGURE 3. NUMBER OF HMOS PARTICIPATING IN MEDICARE+ CHOICE PER COUNTY IN 2001

of the CMS payment $P$, average variable cost $A V C$, the probability of enrollment in Medicare managed care of the representative Medicare eligible $d$, the number of Medicare eligibles in the market $S$, and fixed costs of entry, $F$. These variables are defined as follows:

P: Payment Our regressor of interest is the CMS per-enrollee per-month payment specific to the county. We enter the CMS payment directly and also interact it with an indicator for the BBA regime (1998-2001), which allows the effect of the CMS payment to vary before and after the BBA took effect. These payment variables include bonuses, paid only in 2000 and 2001, equal to $5 \%$ of the per-enrollee payment for the first year, and 3\% of the per-enrollee payment for the second year, that an HMO operates in a previously unserved county.

Although in practice the per-capita payments of CMS to HMOs are adjusted to take into account the demographic and (more recently) risk factors associated with the enrollee, we do not make these adjustments and thus the payment used in our empirical work represents the payment for the average enrollee. The payment for the average enrollee by county of the US in the year 2001 is depicted in Figure 4.

Summary statistics of the CMS per-enrollee monthly payments are listed in Table IV in nominal dollars. Table IV indicates that the average CMS county monthly payment per enrollee rose each year in 
TABLE IV.

SUMMARY STATISTICS OF MONTHLY PER-ENROLLEE CMS PAYMENTS, BY YEAR

\begin{tabular}{lcccc}
\hline Year & Mean & Std. Deviation & Minimum & Maximum \\
\hline 1993 & 301.86 & 55.46 & 168.15 & 598.65 \\
1994 & 314.72 & 58.29 & 171.07 & 653.44 \\
1995 & 332.43 & 62.99 & 177.32 & 678.90 \\
1996 & 372.13 & 70.58 & 207.31 & 881.35 \\
1997 & 394.78 & 76.69 & 220.92 & 767.35 \\
1998 & 417.09 & 62.99 & 367.00 & 782.70 \\
1999 & 427.33 & 62.69 & 379.84 & 798.35 \\
2000 & 449.78 & 56.85 & 401.52 & 809.28 \\
2001 (Jan-Feb) & 460.39 & 56.66 & 414.88 & 825.46 \\
2001 (Mar-Dec) & 498.82 & 41.70 & 475.00 & 833.55 \\
\hline
\end{tabular}

Source: CMS Medicare managed care historical payment files, 1993-2001.

Notes: Figures are in nominal dollars. The BIPA of 2000 raised payments to HMOs effective March 2001. Payments do not include bonuses for operating in previously unserved counties during 2000 and 2001.

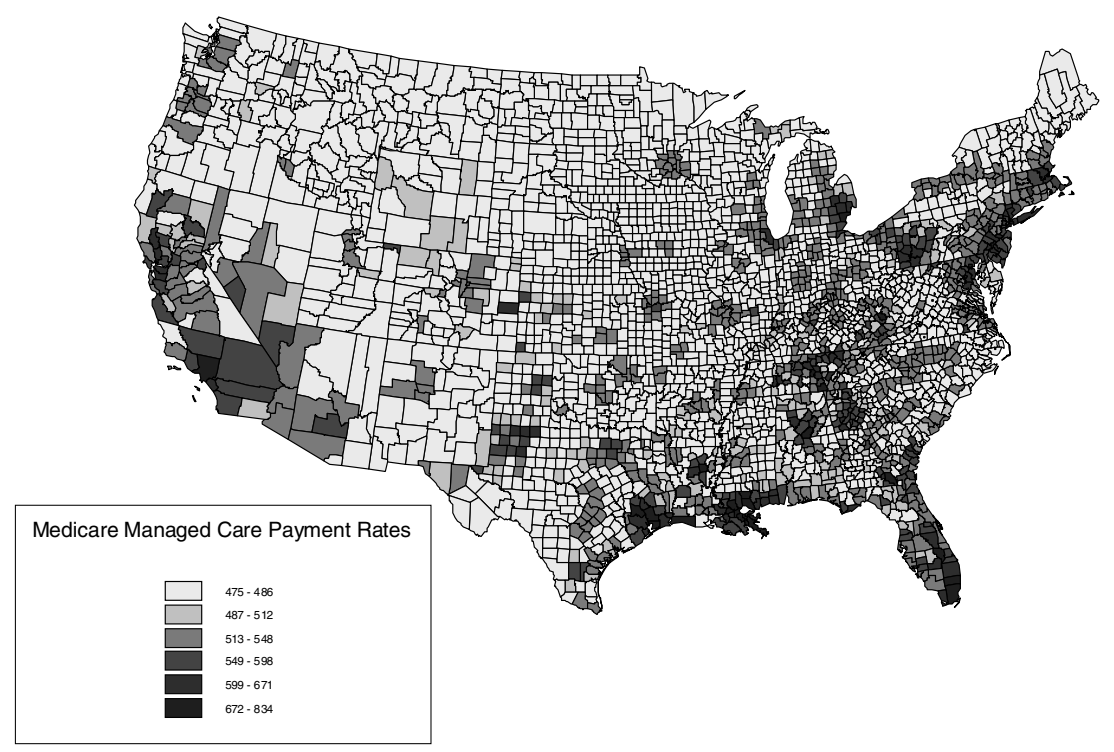

FIGURE 4. MEDICARE+CHOICE MONTHLY PER ENROLLEE PAYMENT RATES BY COUNTY IN 2001

1993-2001. The variance in the county payments rose until 1997, when the BBA was passed in part to reduce disparities in payments across counties. Since 1997, the variance in payments across counties has fallen each year. CMS payments to HMOs are constant during a calendar 
year; the exception to this rule is 2001, when payments were raised effective March 2001 by the Medicare, Medicaid, and SCHIP Benefits Improvement and Protection Act of 2000. We use the March payment rate for 2001 because the dependent variable is also created using March data.

AVC: Average Variable Costs We do not observe the average variable costs of HMOs. We assume that average variable costs in county $c$ in year $t$, denoted $A V C_{c, t}$, have the following structure:

$$
\begin{aligned}
A V C_{c, t}= & \beta_{A} A_{c, 1991}\left(1+\frac{P_{A, t}-P_{A, 1991}}{P_{A, 1991}}\right) \\
& +\beta_{B} B_{c, 1991}\left(1+\frac{P_{B, t}-P_{B, 1991}}{P_{B, 1991}}\right)+\beta_{x} X_{c}+\sum_{t=1994}^{2001} \beta_{t} \mathrm{I}_{t}
\end{aligned}
$$

$A_{c, 1991}$ is the average Medicare Part A (Hospital Insurance) reimbursement per enrollee in county $c$ in 1991; this amount is multiplied by the percent change in Part A costs since 1991, as measured by the CMS Hospital Input Price Index, which is represented in the equation above by $P_{A, t}$. The Hospital Input Price Index tracks changes in the prices of hospital inputs. Likewise, $B_{c, 1991}$ is the average Medicare Part B (Supplementary Medical Insurance) reimbursement per enrollee in county $c$ in 1991; this amount is multiplied by the percent change in Part B costs since 1991, as measured by the CMS Medicare Economic Index, which is represented in the equation above by $P_{B, t}$. The Medicare Economic Index tracks changes in the prices of inputs to outpatient care. It should be noted that the change in costs that we observe over time is that due to prices, not necessarily utilization. It should also be noted that the Hospital Input Price Index and the Medicare Economic Index are nationwide indices and therefore all of the difference across counties in costs is due to the baseline difference in costs in 1991. In our regression model, we will enter the Part A and Part B costs separately because we do not wish to constrain their coefficients to be equal; costs in the two areas may have different impacts on the likelihood that HMOs will participate.

In the average variable costs equation listed above, $X_{c}$ is a vector of county characteristics that may affect costs, specifically: the number of general practitioners in 1990, the number of registered nurses in 1990, the number of hospitals in 1993, and median rent in $1990 .{ }^{23}$ We also include

23. The source of the data on number of doctors is the American Medical Association Physician Masterfile, and that for the number of hospitals is the American Hospital Association Survey of Hospitals. 
as regressors population density and the percent of the population that is urban because geographically dispersed populations may be more costly to serve. Finally, year-specific costs are captured by $I_{t}$, an indicator variable that equals one if the observation is for year $t$.

S: Size of the Market We control for the size of the county market using the number of Medicare beneficiaries in the county in 1990. We also include the percent change in this number 1980-90 to account for the fact that HMOs may prefer to enter growing markets.

F: Fixed Costs of Entry We control for two factors that Brown and Gold (1999) suggest affect the fixed costs of entry into the $\mathrm{M}+\mathrm{C}$ market. The first is whether the HMO already operates in the commercial market in the county. An HMO that has already sunk the costs of establishing a network of health care providers in the county may find it cheaper to enter the Medicare market; that is, there may be economies of scope to participating in multiple managed-care markets in the same county. HMOs that historically participated in the commercial market of the county may in general face lower barriers to entering the $\mathrm{M}+\mathrm{C}$ market.

We do not simply control for the number of HMOs participating in the county's commercial managed care market; because an HMO could enter a county's commercial market for the purpose of subsequently entering its Medicare managed care market, current participation in the commercial market is endogenous. Instead, we control for the number of HMOs in the county in 1980, before the TEFRA of 1982 created the modern $\mathrm{M}+\mathrm{C}$ market. ${ }^{24}$ We also control for the likelihood of HMOs participating in the county commercial market using the percent of the workforce in manufacturing or white-collar jobs in 1990. The presence of these types of employees proxies for the presence of employers likely to demand commercial managed care for their employees.

The second factor that affects the fixed cost of entering a county $\mathrm{M}+\mathrm{C}$ market is whether an $\mathrm{HMO}$ participates in nearby counties. It may be cheaper for an HMO to enter a county adjacent to its current service area because the HMO may already be familiar with local providers and have acquired information about the local market. To proxy for the likelihood of participating in adjacent counties, we control for the total number of Medicare beneficiaries in 1990 in all adjacent counties and its percent growth in 1980-1990.

d: Probability that Medicare Eligibles will Enroll in Medicare Managed Care It has repeatedly been found that relatively healthy Medicare

24. The National HMO Census of Prepaid Plans is source of the data on HMO participation in commercial markets. 
beneficiaries are the most likely to enroll in managed care. ${ }^{25}$ In order to capture cross-county differences in the proportion of healthy beneficiaries (and therefore demand for Medicare managed care), we control for per capita income, the poverty rate among the county's elderly, the percent of adults with a high school diploma, and the percent of adults with a college degree. ${ }^{26}$ Each of these variables was measured in 1990.

Summary statistics for the variables used in this paper appear in Table V.

We exclude from the regression the characteristics of the individual participating HMOs because, as mentioned earlier, HMO entry into $\mathrm{M}+\mathrm{C}$ is an example of a multiple-agent discrete-move game. It is likely that multiple equilibria exist, and that the number of firms participating is determined but which individual HMOs participate is to some extent random.

\section{EMPIRICAL RESULTS}

The results of the ordered probit regression of the number of HMOs participating in $\mathrm{M}+\mathrm{C}$ are presented in Table VI. For all the analyses reported in this paper, the number of Medicare beneficiaries residing in the county was used as a population weight in the regression, and standard errors are cluster-corrected to account for possible dependence in errors within each county over time.

The coefficients on CMS payment and CMS payment interacted with BBA regime are positive and statistically significant at the $1 \%$ level, which is consistent with our hypothesis that controlling for costs, a higher payment is associated with the participation of more HMOs. The coefficient on estimated Part A (Hospital Insurance) costs in a county is statistically significant and negative; this is consistent with the view that HMOs are wary of entering counties with sicker patients (who typically have higher hospital costs), for fear of adverse selection and lower profits. The coefficient on Part B (Supplementary Medical) costs is also negative but not statistically significant.

As described in Section 2, the coefficients presented in Table VI can be used to calculate the CMS payments necessary in each county to support a given number of HMOs. These payment thresholds are

25. See, for example, Chapter 15 of Physician Payment Review Commission (1996), GAO Report 97-160 (1997), and the summary in Glied (2000). Possible reasons that the relatively healthy are more likely to enroll in managed care are that they are less likely to have an established health care provider and that they may be less risk averse.

26. We assume that the per capita income and education of Medicare beneficiaries track those of the entire adult population in the county. The source of data on the poverty rate among the elderly is the Bureau of Census' Small Area Income Poverty Estimates and that for per capita income is the US Department of Commerce. 


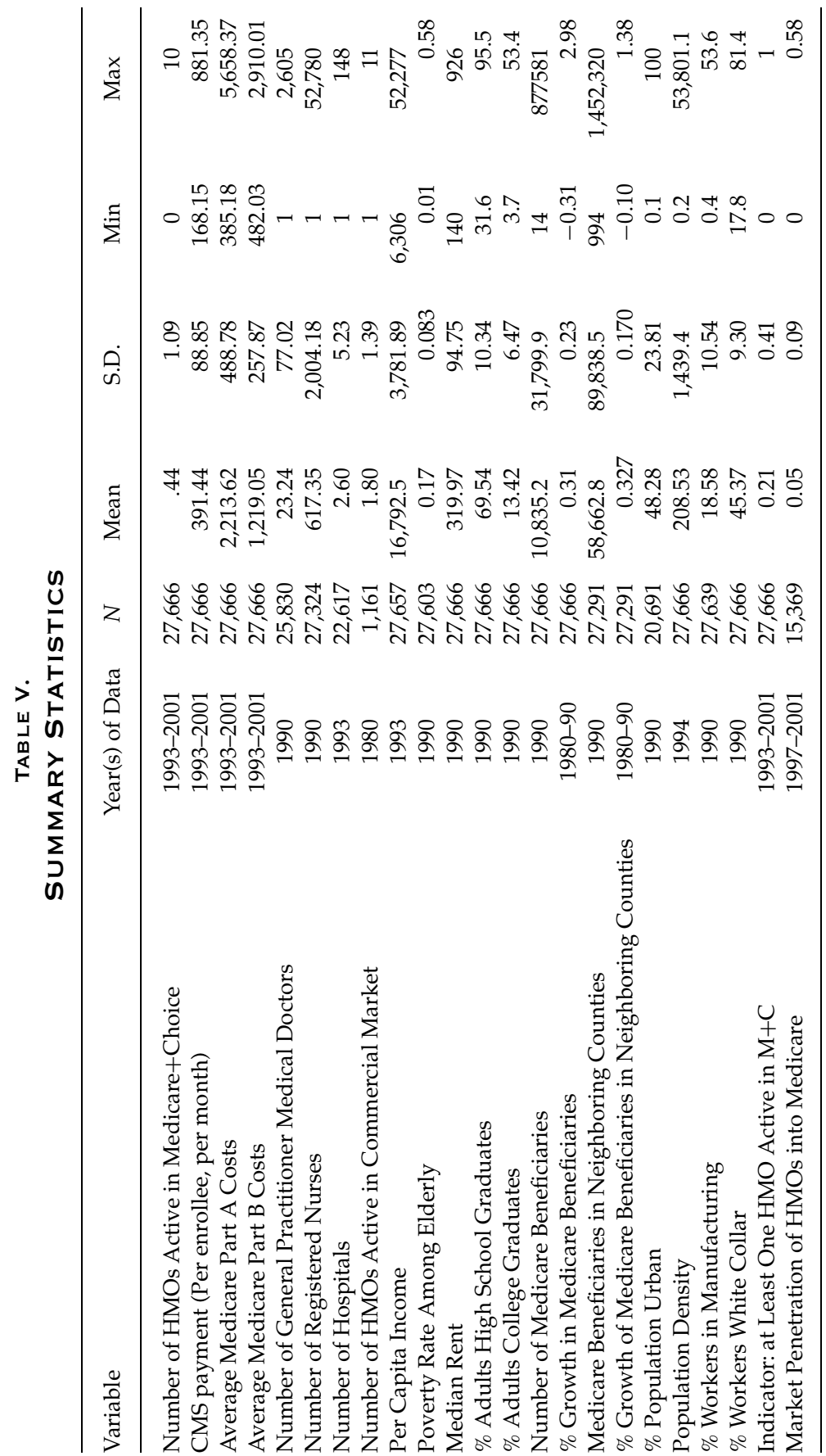




\section{TABLE Vi. \\ ORDERED PROBIT REGRESSION \\ DEPENDENT VARIABLE: NUMBER OF HMOS \\ PARTICIPATING IN MEDICARE+CHOICE IN COUNTY}

\begin{tabular}{|c|c|c|}
\hline Variable & Coefficient & Z Score \\
\hline \multicolumn{3}{|l|}{ Payment } \\
\hline CMS Payment & 0.0092 & 6.68 \\
\hline CMS Payment * Indicator for 1998-2001 & 0.0027 & 4.59 \\
\hline \multicolumn{3}{|l|}{ Indicator Variables for Year } \\
\hline 1994 & 0.2258 & 4.44 \\
\hline 1995 & 0.5625 & 6.96 \\
\hline 1996 & 0.7347 & 5.73 \\
\hline 1997 & 0.9344 & 6.17 \\
\hline 1998 & -0.3311 & -1.17 \\
\hline 1999 & -0.4289 & -1.52 \\
\hline 2000 & -0.7010 & -2.33 \\
\hline 2001 & -1.551 & -4.60 \\
\hline \multicolumn{3}{|l|}{ Variables Affecting Average Variable Costs } \\
\hline Average Medicare Part A Costs & -0.0008 & -4.39 \\
\hline Average Medicare Part B Costs & -.00008 & -0.03 \\
\hline Number of General Practitioners & 0.0018 & 2.02 \\
\hline Number of Registered Nurses & -0.0002 & -2.83 \\
\hline Number of Hospitals & 0.0199 & 2.00 \\
\hline Median Rent & 0.0027 & 3.96 \\
\hline Population Density & 0.000002 & 0.80 \\
\hline Percent Population in Urban Areas & 0.0080 & 3.84 \\
\hline \multicolumn{3}{|l|}{ Measures of the Size of the Market } \\
\hline Number of Medicare Beneficiaries & 0.000004 & 1.14 \\
\hline Percent Growth in Medicare Beneficiaries & -0.5307 & -2.34 \\
\hline \multicolumn{3}{|l|}{ Variables Affecting Fixed Costs of Entry } \\
\hline Number of HMOs in County in 1980 & -0.0127 & -0.23 \\
\hline Percent Workforce in Manufacturing & 0.0009 & 0.14 \\
\hline Percent Workforce White Collar & 0.0526 & 4.12 \\
\hline $\begin{array}{l}\text { Number of Medicare Beneficiaries } \\
\text { in All Adjacent Counties }\end{array}$ & 0.000002 & 4.48 \\
\hline $\begin{array}{l}\text { Percent Growth in Medicare Beneficiaries } \\
\text { in All Adjacent Counties }\end{array}$ & 0.6245 & 1.89 \\
\hline \multicolumn{3}{|l|}{ Variables Affecting the Probability of Enrollment } \\
\hline Per Capita Income & -0.00003 & -1.95 \\
\hline Poverty Rate Among Elderly & -3.779 & -2.94 \\
\hline Percent of Adults with High School Diploma & 0.0054 & 0.47 \\
\hline Percent of Adults with College Degree & -0.034 & -2.73 \\
\hline Number of Observations & 27,666 & \\
\hline Log Likelihood & $-31,933.94$ & \\
\hline
\end{tabular}

Notes: Z scores reflect cluster-corrections of standard errors by county.

Coefficients on indicator variables for missing values are omitted.

Regression is weighted by Medicare population of county. 
TABLE VII.

ESTIMATED MAXIMUM PAYMENT NECESSARY TO SUPPORT A GIVEN NUMBER OF HMOS IN MEDICARE+CHOICE IN A CERTAin PERCENT OF COUNTIES IN YeAR 2001

\begin{tabular}{lcccccc}
\hline \multirow{2}{*}{$\begin{array}{l}\text { Percent of Counties } \\
\text { with at Least } N\end{array}$} & \multicolumn{5}{c}{ Minimum Number of HMOs Participating in County } \\
\cline { 2 - 7 } HMOs Participating & 1 & 2 & 3 & 4 & 5 & 6 \\
\hline \multirow{2}{*}{10} & 481.25 & 538.80 & 593.80 & 649.33 & 698.89 & 741.98 \\
& $(9.56)$ & $(16.36)$ & $(26.02)$ & $(43.25)$ & $(54.62)$ & $(66.31)$ \\
20 & 517.57 & 575.12 & 630.12 & 685.64 & 735.20 & 778.29 \\
& $(12.51)$ & $(27.12)$ & $(37.99)$ & $(55.60)$ & $(66.96)$ & $(78.71)$ \\
30 & 541.37 & 598.92 & 653.92 & 709.45 & 759.01 & 802.10 \\
& $(18.31)$ & $(33.63)$ & $(44.79)$ & $(62.43)$ & $(73.74)$ & $(85.50)$ \\
40 & 561.64 & 619.19 & 674.19 & 729.71 & 779.27 & 822.36 \\
& $(21.83)$ & $(37.33)$ & $(48.63)$ & $(66.28)$ & $(77.59)$ & $(89.33)$ \\
50 & 580.95 & 638.50 & 693.50 & 749.03 & 798.59 & 841.67 \\
& $(24.62)$ & $(40.20)$ & $(51.54)$ & $(69.20)$ & $(80.49)$ & $(92.21)$ \\
60 & 602.74 & 660.29 & 715.29 & 770.82 & 820.38 & 863.46 \\
& $(27.61)$ & $(43.23)$ & $(54.60)$ & $(72.27)$ & $(83.55)$ & $(95.28)$ \\
70 & 623.46 & 681.01 & 736.01 & 791.53 & 841.10 & 884.18 \\
& $(31.18)$ & $(46.85)$ & $(58.21)$ & $(75.90)$ & $(87.19)$ & $(98.90)$ \\
80 & 650.56 & 708.11 & 763.11 & 818.64 & 868.20 & 911.28 \\
& $(35.42)$ & $(51.08)$ & $(62.43)$ & $(80.11)$ & $(91.42)$ & $(103.11)$ \\
90 & 686.54 & 744.09 & 799.09 & 854.62 & 904.18 & 947.26 \\
& $(39.52)$ & $(55.12)$ & $(66.41)$ & $(84.00)$ & $(95.31)$ & $(106.98)$ \\
100 & 877.26 & 934.81 & 989.81 & $1,045.34$ & $1,094.90$ & $1,137.99$ \\
& $(61.73)$ & $(75.13)$ & $(85.23)$ & $(101.65)$ & $(112.35)$ & $(123.22)$ \\
& & & & & & \\
\hline
\end{tabular}

Notes: Calculated using ordered probit coefficients reported in Table VI. Bootstrap standard errors in parentheses.

presented in Table VII. Bootstrapped standard errors are presented in parentheses below the estimated payment thresholds. ${ }^{27}$

The payment threshold necessary to support a given number of Medicare HMOs varies by county. Table VII presents the year 2001 thresholds for ten counties: the counties at every tenth percentile in the distribution. In order to support a single $\mathrm{HMO}$ in $\mathrm{M}+\mathrm{C}$ in $10 \%$ of all counties, it is necessary for CMS to pay $\$ 481$ per average enrollee per month in the marginal county. In order to support one $\mathrm{HMO}$ in $\mathrm{M}+\mathrm{C}$

27. Derivation of standard errors for the thresholds is difficult because the thresholds are non-linear functions of several random variables. We follow the recommendation of Efron and Tibshirani (1993) and conduct 200 replications to estimate the bootstrap standard errors. The standard errors may be irrelevant because our sample is the entire population of counties in the contiguous 48 states. However, the standard errors are meaningful if one allows for measurement error in the dependent variable or one interprets the sample (which covers 1993-2001) as drawn from all possible years. 
in half of all counties, the payment in the marginal county must be at least $\$ 581$. To support a single HMO in every county, CMS would have to pay $\$ 877$ in the marginal county.

Table VII also lists the CMS payment thresholds necessary to support multiple HMOs in county $\mathrm{M}+\mathrm{C}$ markets. CMS may desire multiple HMOs in each market because the competition between the HMOs for market share leads to lower out-of-pocket costs and additional benefits for enrollees. A comparison across columns of Table VII suggests that $\$ 50-\$ 60$ more per enrollee per month is necessary to support each additional HMO.

There is also an interesting pattern across rows. The monthly payment necessary to support a given number of HMOs in 10\% more counties is less than $\$ 50$ until the last $10 \%$ of counties. To ensure that the last $10 \%$ of counties also support $N$ HMOs requires a dramatically larger increment in payment, roughly $\$ 190$. There exists a group of counties, amounting to no more than $10 \%$ of all counties, in which it is extremely expensive to support HMOs in $\mathrm{M}+\mathrm{C}$.

Table VIII compares the mean characteristics of two groups of counties: those in which CMS payments in the year 2001 were more than the estimated payment necessary to support the participation of one $\mathrm{HMO}$ in $\mathrm{M}+\mathrm{C}$, and those in which the payment was less than that threshold. The table also lists the difference in means and the $t$-statistic associated with the test of the hypothesis that the means are equal across the two groups of counties.

In the year 2001, 561 counties in our sample received CMS payments that exceeded the estimated payment necessary to support one $\mathrm{HMO}$, while 2,513 counties were assigned payments less than the singleHMO threshold. Table VIII indicates that counties assigned payments greater than the estimated single-HMO threshold have both higher CMS payments and higher Part A and B Medicare costs than the counties assigned payments less than the threshold. In addition, the counties with above-threshold payments have many more hospitals and general practitioners, much larger populations of Medicare beneficiaries, and have in general better educated and wealthier populations. Each of these differences is statistically significant at the $1 \%$ significance level.

If a below-threshold payment can be interpreted as an underestimate by CMS of costs in that county, then our results suggest that CMS tends to underestimate the costs of HMO participation in sparsely populated counties. Several studies noted that, under the TEFRA payment scheme that was used prior to 1998, rural counties were particularly unlikely to be served by HMOs. ${ }^{28}$ Passage of the BBA was intended

28. See, for example, Serrato, Brown, and Bergeron (1995). 
TABLE VIII.

\section{DIFFERENCE IN MEAN CHARACTERISTICS BETWEEN \\ COUNTIES WITH ACTUAL PAYMENTS ABOVE AND BELOW \\ ESTIMATED PAYMENT THRESHOLD FOR ONE HMO TO \\ PARTICIPATE IN MEDICARE+CHOICE IN THE YeAR 2001}

\begin{tabular}{lrrrr}
\hline & $\begin{array}{c}\text { Mean for } \\
\text { Counties } \\
\text { with Actual } \\
\text { Payment }> \\
\text { Threshold }\end{array}$ & $\begin{array}{c}\text { Mean for } \\
\text { Counties } \\
\text { with Actual } \\
\text { Payment }<\end{array}$ & $\begin{array}{c}\text { Difference } \\
\text { Threshold } \\
\text { in Means }\end{array}$ & $\begin{array}{c}\text { t-Statistic } \\
\text { for } \\
\text { Equality } \\
\text { of Means }\end{array}$ \\
\hline Number of Participating HMOs, 2001 & 1.50 & 0.15 & 1.34 & 19.75 \\
Monthly CMS Payment, 2001 & 546.35 & 497.10 & 49.24 & 20.23 \\
Average Medicare Part A Costs, 1991 & $1,957.62$ & $1,832.73$ & 124.89 & 6.13 \\
Average Medicare Part B Costs, 1991 & $1,226.81$ & $1,054.92$ & 171.88 & 14.27 \\
Number of General Practitioners, 1990 & 81.76 & 9.15 & 72.61 & 10.66 \\
Number of Hospitals, 1993 & 6.72 & 1.54 & 5.18 & 11.38 \\
Per Capita Income, 1993 & $20,356.56$ & $15,995.37$ & $4,361.19$ & 21.65 \\
Poverty Rate Among Elderly, 1990 & 10.08 & 18.73 & -8.64 & -30.52 \\
\% Adults High School Graduates, 1990 & 78.29 & 67.59 & 10.70 & 31.01 \\
\% Adults College Graduates, 1990 & 20.59 & 11.82 & 8.77 & 25.38 \\
Number Medicare Beneficiaries, 1990 & $39,644.31$ & $4,399.75$ & $35,244.56$ & 12.56 \\
\% Population Urban, 1990 & 72.34 & 40.79 & 31.54 & 29.89 \\
Population Density, 1994 & 912.11 & 51.47 & 860.64 & 6.22 \\
Number of Counties & 561 & 2,513 & & \\
\hline
\end{tabular}

to eliminate such disparities by raising payments more quickly in lowpayment than high-payment counties. We find that even 3 years after the BBA took effect, counties with CMS payment insufficient to support HMO participation tend to be far less populous than counties that receive what we estimate to be sufficient payment. ${ }^{29}$

Table IX lists the estimated percent of all counties in which a given number of HMOs would be supported for various monthly payments in 2001. The first row of the table confirms that if the monthly payment were zero, then HMOs would participate in $\mathrm{M}+\mathrm{C}$ in $0 \%$ of counties. The first few rows of the table reveal an interesting pattern: one county (which represents $0.03 \%$ of all counties) requires the lowest payment to support HMOs in $\mathrm{M}+\mathrm{C}$. In particular, this county requires only $\$ 200$

29. Another piece of evidence that the BBA has not worked as intended appears in Table III; specifically, the relationship between the number of Medicare beneficiaries in a county and the probability of a participating Medicare HMO is stronger in 2001 than in 1993. 
TABLE IX.

Estimated Percent of All Counties with a Given NUMBER OF HMOS PARTICIPATING IN MEDICARE+CHOICE, BY HYPOTHETICAL COUNTY PAYMENT RATE IN YEAR 2001

\begin{tabular}{|c|c|c|c|c|c|c|c|}
\hline \multirow{2}{*}{$\begin{array}{l}\text { Monthly } \\
\text { Payment (\$) }\end{array}$} & \multicolumn{7}{|c|}{ Number of HMOs Participating in County } \\
\hline & 0 & 1 & 2 & 3 & 4 & 5 & $6+$ \\
\hline \multirow[t]{2}{*}{0} & 100 & 0 & 0 & 0 & 0 & 0 & 0 \\
\hline & $(0.05)$ & $(0.02)$ & $(0.01)$ & $(0.00)$ & $(0.00)$ & $(0.01)$ & $(0.08)$ \\
\hline \multirow[t]{2}{*}{100} & 100 & 0 & 0 & 0 & 0 & 0 & 0 \\
\hline & $(0.08)$ & $(0.04)$ & $(0.02)$ & $(0.01)$ & $(0.01)$ & $(0.00)$ & $(0.05)$ \\
\hline \multirow[t]{2}{*}{200} & 99.97 & 0.03 & 0 & 0 & 0 & 0 & 0 \\
\hline & $(0.13)$ & $(0.08)$ & $(0.04)$ & $(0.02)$ & $(0.01)$ & $(0.01)$ & (0.06) \\
\hline \multirow[t]{2}{*}{300} & 99.84 & 0.10 & .03 & 0.03 & 0 & 0 & 0 \\
\hline & $(0.42)$ & $(0.32)$ & $(0.08)$ & $(0.04)$ & $(0.03)$ & $(0.02)$ & (0.05) \\
\hline \multirow[t]{2}{*}{400} & 98.70 & 1.01 & 0.20 & 0.07 & 0 & 0.03 & 0 \\
\hline & $(1.23)$ & $(0.93)$ & $(0.27)$ & $(0.09)$ & $(0.04)$ & $(0.03)$ & (0.05) \\
\hline \multirow[t]{2}{*}{500} & 85.91 & 10.21 & 2.86 & 0.75 & 0.16 & 0.03 & 0.07 \\
\hline & $(1.97)$ & (1.55) & $(0.67)$ & $(0.29)$ & $(0.94)$ & $(0.06)$ & $(0.06)$ \\
\hline \multirow[t]{2}{*}{600} & 41.18 & 28.37 & 19.06 & 8.20 & 2.41 & 0.49 & 0.29 \\
\hline & (10.51) & (3.69) & $(5.40)$ & $(2.31)$ & $(.72)$ & $(0.21)$ & (0.13) \\
\hline \multirow[t]{2}{*}{700} & 7.29 & 15.03 & 24.53 & 27.26 & 15.68 & 6.54 & 3.68 \\
\hline & (8.74) & $(8.26)$ & $(4.83)$ & $(6.84)$ & (5.89) & $(2.62)$ & (1.59) \\
\hline \multirow[t]{2}{*}{800} & 0.55 & 2.21 & 7.09 & 16.36 & 23.26 & 21.57 & 28.95 \\
\hline & $(3.26)$ & $(7.40)$ & $(8.84)$ & $(7.63)$ & (7.11) & $(7.02)$ & (12.75) \\
\hline \multirow[t]{2}{*}{900} & 0 & 0.23 & 0.62 & 2.54 & 7.51 & 12.39 & 76.71 \\
\hline & $(0.85)$ & (3.09) & (6.67) & (11.57) & (8.38) & (7.16) & (26.81) \\
\hline \multirow[t]{2}{*}{1000} & 0 & 0 & 0 & 0.26 & 0.68 & 2.02 & 97.04 \\
\hline & $(0.14)$ & (1.10) & $(2.92)$ & $(7.78)$ & (9.60) & $(8.82)$ & $(26.52)$ \\
\hline \multirow[t]{2}{*}{1100} & 0 & 0 & 0 & 0 & 0 & 0.26 & 99.74 \\
\hline & $(0.02)$ & $(0.24)$ & (1.34) & $(3.81)$ & (5.66) & (8.19) & (17.21) \\
\hline \multirow[t]{2}{*}{1200} & 0 & 0 & 0 & 0 & 0 & 0 & 100 \\
\hline & $(0.00)$ & $(0.05)$ & $(0.42)$ & (1.96) & (2.83) & (4.54) & (8.77) \\
\hline
\end{tabular}

Notes: Calculated using ordered probit coefficients reported in Table VI. Bootstrap standard errors in parentheses.

per enrollee per month to support one HMO, \$300 monthly payments to support three HMOs, and \$400 a month to support five HMOs. ${ }^{30}$

At the other end of the spectrum, the last rows indicate that a few counties require particularly large payments in order to support

30. The county that can support an HMO for the lowest payment is California's Los Angeles County. There is no single reason that LA County can support an HMO for the lowest payment; instead, LA County has high values for many variables positively correlated with HMO participation in M+C: high CMS payment, a large number of general practitioners and hospitals, a high percentage of residents living in urban areas, and high populations in neighboring counties. 
TABLE $\mathbf{X}$.

Estimated Percent of All Medicare Beneficiaries

LIVING IN COUNTIES WITH A GIVEN NUMBER OF HMOS PARTICIPATING IN MEDICARE+CHOICE, BY HYPOTHETICAL COUNTY PAYMENT RATE IN YEAR 2001

\begin{tabular}{|c|c|c|c|c|c|c|c|}
\hline \multirow{2}{*}{$\begin{array}{l}\text { Monthly } \\
\text { Payment (\$) }\end{array}$} & \multicolumn{7}{|c|}{ Number of HMOs Participating in County } \\
\hline & 0 & 1 & 2 & 3 & 4 & 5 & $6+$ \\
\hline 0 & $\begin{array}{c}100 \\
(2.36)\end{array}$ & $\begin{array}{c}0 \\
(0.80)\end{array}$ & $\begin{array}{c}0 \\
(0.67)\end{array}$ & $\begin{array}{c}0 \\
(0.06)\end{array}$ & $\begin{array}{c}0 \\
(0.19)\end{array}$ & $\begin{array}{c}0 \\
(0.94)\end{array}$ & $\begin{array}{c}0 \\
(2.04)\end{array}$ \\
\hline 100 & $\begin{array}{c}100 \\
(2.92)\end{array}$ & $\begin{array}{c}0 \\
(1.65)\end{array}$ & $\begin{array}{c}0 \\
(1.20)\end{array}$ & $\begin{array}{c}0 \\
(0.66)\end{array}$ & $\begin{array}{c}0 \\
(0.49)\end{array}$ & $\begin{array}{c}0 \\
(0.19)\end{array}$ & $\begin{array}{c}0 \\
(2.19)\end{array}$ \\
\hline 200 & $\begin{array}{l}97.36 \\
(3.46)\end{array}$ & $\begin{array}{c}2.64 \\
(1.81)\end{array}$ & $\begin{array}{c}0 \\
(1.70)\end{array}$ & $\begin{array}{c}0 \\
(1.45)\end{array}$ & $\begin{array}{c}0 \\
(0.64)\end{array}$ & $\begin{array}{c}0 \\
(0.53)\end{array}$ & $\begin{array}{c}0 \\
(2.19)\end{array}$ \\
\hline 300 & $\begin{array}{c}95.6 \\
(5.26)\end{array}$ & $\begin{array}{c}1.08 \\
(3.00)\end{array}$ & $\begin{array}{c}0.68 \\
(1.66)\end{array}$ & $\begin{array}{c}2.64 \\
(1.58)\end{array}$ & $\begin{array}{c}0 \\
(1.63)\end{array}$ & $\begin{array}{c}0 \\
(1.18)\end{array}$ & $\begin{array}{c}0 \\
(2.24)\end{array}$ \\
\hline 400 & $\begin{array}{l}87.43 \\
(8.97)\end{array}$ & $\begin{array}{c}6.31 \\
(5.40)\end{array}$ & $\begin{array}{c}2.53 \\
(2.53)\end{array}$ & $\begin{array}{c}1.09 \\
(1.62)\end{array}$ & $\begin{array}{c}0 \\
(1.45)\end{array}$ & $\begin{array}{c}2.64 \\
(1.58)\end{array}$ & $\begin{array}{c}0 \\
(2.67)\end{array}$ \\
\hline 500 & $\begin{array}{l}48.47 \\
(4.74)\end{array}$ & $\begin{array}{l}28.06 \\
(3.64)\end{array}$ & $\begin{array}{l}12.34 \\
(3.34)\end{array}$ & $\begin{array}{c}4.90 \\
(2.36)\end{array}$ & $\begin{array}{c}2.51 \\
(1.68)\end{array}$ & $\begin{array}{c}0.41 \\
(1.11)\end{array}$ & $\begin{array}{c}3.32 \\
(2.85)\end{array}$ \\
\hline 600 & $\begin{array}{l}12.00 \\
(3.76)\end{array}$ & $\begin{array}{l}16.72 \\
(3.03)\end{array}$ & $\begin{array}{l}25.04 \\
(4.54)\end{array}$ & $\begin{array}{l}24.76 \\
(3.83)\end{array}$ & $\begin{array}{l}11.83 \\
(2.65)\end{array}$ & $\begin{array}{c}3.39 \\
(1.67)\end{array}$ & $\begin{array}{c}6.25 \\
(3.39)\end{array}$ \\
\hline 700 & $\begin{array}{c}1.34 \\
(2.26)\end{array}$ & $\begin{array}{c}3.49 \\
(3.86)\end{array}$ & $\begin{array}{l}10.20 \\
(3.60)\end{array}$ & $\begin{array}{l}17.05 \\
(4.26)\end{array}$ & $\begin{array}{l}24.01 \\
(4.73)\end{array}$ & $\begin{array}{l}20.93 \\
(5.09)\end{array}$ & $\begin{array}{c}22.98 \\
(6.25)\end{array}$ \\
\hline 800 & $\begin{array}{c}0.07 \\
(0.70)\end{array}$ & $\begin{array}{c}0.37 \\
(2.06)\end{array}$ & $\begin{array}{c}1.41 \\
(3.71)\end{array}$ & $\begin{array}{c}4.22 \\
(6.17)\end{array}$ & $\begin{array}{c}9.99 \\
(5.09)\end{array}$ & $\begin{array}{l}13.72 \\
(4.48)\end{array}$ & $\begin{array}{c}70.22 \\
(17.61)\end{array}$ \\
\hline 900 & $\begin{array}{c}0 \\
(0.16)\end{array}$ & $\begin{array}{c}0.03 \\
(0.72)\end{array}$ & $\begin{array}{c}0.09 \\
(1.90)\end{array}$ & $\begin{array}{c}0.48 \\
(4.71)\end{array}$ & $\begin{array}{c}1.52 \\
(5.38)\end{array}$ & $\begin{array}{c}2.97 \\
(5.93)\end{array}$ & $\begin{array}{c}94.91 \\
(17.26)\end{array}$ \\
\hline 1000 & $\begin{array}{c}0 \\
(0.02)\end{array}$ & $\begin{array}{c}0 \\
(0.22)\end{array}$ & $\begin{array}{c}0 \\
(0.75)\end{array}$ & $\begin{array}{c}0.03 \\
(2.33)\end{array}$ & $\begin{array}{c}0.10 \\
(3.65)\end{array}$ & $\begin{array}{c}0.37 \\
(4.85)\end{array}$ & $\begin{array}{c}99.51 \\
(11.13)\end{array}$ \\
\hline 1100 & $\begin{array}{c}0 \\
(0.00)\end{array}$ & $\begin{array}{c}0 \\
(0.04)\end{array}$ & $\begin{array}{c}0 \\
(0.29)\end{array}$ & $\begin{array}{c}0 \\
(1.11)\end{array}$ & $\begin{array}{c}0 \\
(1.68)\end{array}$ & $\begin{array}{c}0.03 \\
(3.00)\end{array}$ & $\begin{array}{c}99.97 \\
(5.73)\end{array}$ \\
\hline 1200 & $\begin{array}{c}0 \\
(0.00)\end{array}$ & $\begin{array}{c}0 \\
(0.01)\end{array}$ & $\begin{array}{c}0 \\
(0.08)\end{array}$ & $\begin{array}{c}0 \\
(0.48)\end{array}$ & $\begin{array}{c}0 \\
(0.89)\end{array}$ & $\begin{array}{c}0 \\
(1.46)\end{array}$ & $\begin{array}{l}100 \\
(2.78)\end{array}$ \\
\hline
\end{tabular}

Notes: Calculated using ordered probit coefficients reported in Table VI.

Bootstrap standard errors in parentheses.

any HMOs; the most expensive counties require no less than $\$ 800$ a month to support a single HMO in $\mathrm{M}+\mathrm{C}$. Table IX also indicates that a payment between $\$ 500$ and $\$ 600$ a month would be necessary in the marginal county to support some HMOs in half of US counties.

Table $X$ reports the percent of beneficiaries who would live in counties with the participation of varying numbers of HMOs by the county payment rate in 2001. A comparison of Tables IX and X indicates that the county requiring the lowest payment to support an $\mathrm{HMO}$ represents only $0.03 \%$ of all counties but is home to $2.64 \%$ of all Medicare 
TABLE XI.

ESTIMATED MAXIMUM PAYMENT NECESSARY TO SUPPORT A GIVEN NUMBER OF HMOS IN MEDICARE+CHOICE IN Counties housing a given Percent of All Medicare BENEFICIARIES IN YEAR 2001

\begin{tabular}{|c|c|c|c|c|c|c|}
\hline \multirow{2}{*}{$\begin{array}{l}\text { Percent of Medicare } \\
\text { Beneficiaries Living } \\
\text { in a County with at } \\
\text { Least } N \text { HMOs } \\
\text { Participating }\end{array}$} & \multicolumn{6}{|c|}{ Minimum Number of HMOs Participating in County } \\
\hline & 1 & 2 & 3 & 4 & 5 & 6 \\
\hline 10 & $\begin{array}{l}383.39 \\
(85.64)\end{array}$ & $\begin{array}{l}440.94 \\
(77.36)\end{array}$ & $\begin{array}{c}495.93 \\
(73.26)\end{array}$ & $\begin{array}{l}551.46 \\
(70.52)\end{array}$ & $\begin{array}{l}601.02 \\
(70.66)\end{array}$ & $\begin{array}{l}644.11 \\
(72.00)\end{array}$ \\
\hline 20 & $\begin{array}{l}428.74 \\
(39.03)\end{array}$ & $\begin{array}{l}486.29 \\
(25.56)\end{array}$ & $\begin{array}{c}541.29 \\
(18.73)\end{array}$ & $\begin{array}{l}596.81 \\
(19.98)\end{array}$ & $\begin{array}{l}646.37 \\
(27.55)\end{array}$ & $\begin{array}{l}689.46 \\
(37.27)\end{array}$ \\
\hline 30 & $\begin{array}{l}453.11 \\
(32.38)\end{array}$ & $\begin{array}{l}510.66 \\
(19.09)\end{array}$ & $\begin{array}{c}565.65 \\
(13.80)\end{array}$ & $\begin{array}{l}621.18 \\
(20.91)\end{array}$ & $\begin{array}{l}670.74 \\
(30.50)\end{array}$ & $\begin{array}{l}713.83 \\
(41.44)\end{array}$ \\
\hline 40 & $\begin{array}{l}475.69 \\
(23.22)\end{array}$ & $\begin{array}{c}533.24 \\
(12.20)\end{array}$ & $\begin{array}{c}588.24 \\
(13.16)\end{array}$ & $\begin{array}{l}643.77 \\
(27.44)\end{array}$ & $\begin{array}{l}693.33 \\
(38.24)\end{array}$ & $\begin{array}{c}736.42 \\
(49.69)\end{array}$ \\
\hline 50 & $\begin{array}{l}496.09 \\
(16.35)\end{array}$ & $\begin{array}{c}553.64 \\
(11.34)\end{array}$ & $\begin{array}{c}608.64 \\
(18.01)\end{array}$ & $\begin{array}{l}664.16 \\
(34.42)\end{array}$ & $\begin{array}{l}713.73 \\
(45.39)\end{array}$ & $\begin{array}{l}756.81 \\
(57.01)\end{array}$ \\
\hline 60 & $\begin{array}{l}516.37 \\
(10.95)\end{array}$ & $\begin{array}{l}573.92 \\
(15.93)\end{array}$ & $\begin{array}{l}628.92 \\
(25.18)\end{array}$ & $\begin{array}{l}684.45 \\
(42.45)\end{array}$ & $\begin{array}{l}734.01 \\
(53.57)\end{array}$ & $\begin{array}{c}777.09 \\
(65.33)\end{array}$ \\
\hline 70 & $\begin{array}{c}539.03 \\
(11.52)\end{array}$ & $\begin{array}{l}596.58 \\
(23.97)\end{array}$ & $\begin{array}{l}651.58 \\
(34.19)\end{array}$ & $\begin{array}{l}707.11 \\
(51.77)\end{array}$ & $\begin{array}{c}756.67 \\
(62.94)\end{array}$ & $\begin{array}{c}799.76 \\
(74.73)\end{array}$ \\
\hline 80 & $\begin{array}{c}567.89 \\
(16.51)\end{array}$ & $\begin{array}{l}625.44 \\
(31.14)\end{array}$ & $\begin{array}{c}680.44 \\
(41.96)\end{array}$ & $\begin{array}{l}735.96 \\
(59.56)\end{array}$ & $\begin{array}{l}785.52 \\
(70.73)\end{array}$ & $\begin{array}{l}828.61 \\
(82.48)\end{array}$ \\
\hline 90 & $\begin{array}{l}610.38 \\
(24.80)\end{array}$ & $\begin{array}{c}667.93 \\
(40.22)\end{array}$ & $\begin{array}{c}722.93 \\
(51.39)\end{array}$ & $\begin{array}{c}778.46 \\
(68.98)\end{array}$ & $\begin{array}{c}828.02 \\
(80.19)\end{array}$ & $\begin{array}{c}871.11 \\
(91.92)\end{array}$ \\
\hline 100 & $\begin{array}{c}877.26 \\
(55.11)\end{array}$ & $\begin{array}{l}934.81 \\
(69.02)\end{array}$ & $\begin{array}{c}989.81 \\
(79.50)\end{array}$ & $\begin{array}{r}1,045.34 \\
(96.37)\end{array}$ & $\begin{array}{c}1,094.90 \\
(107.23)\end{array}$ & $\begin{array}{r}1,137.99 \\
(118.34)\end{array}$ \\
\hline
\end{tabular}

Notes: Calculated using ordered probit coefficients reported in Table VI. Bootstrap standard errors in parentheses.

beneficiaries. The fact that more heavily populated counties require lower payments to support HMOs in this program explains why, for a given payment, the percentage of Medicare beneficiaries living in a county with a participating $\mathrm{HMO}$ will exceed the percentage of counties with a participating HMO. Although Table IX indicated that a monthly payment of $\$ 500-\$ 600$ in the marginal county was necessary to support HMOs in half of US counties, Table $X$ indicates that a payment of less than $\$ 500$ per month in the marginal county is sufficient to provide the option of $\mathrm{M}+\mathrm{C}$ to half of all Medicare beneficiaries.

Table XI lists the estimated maximum payment necessary in 2001 to have a certain percent of Medicare beneficiaries living in counties with a given number of participating HMOs. To support one HMO 
in counties housing half of all Medicare beneficiaries would require a payment of $\$ 496$. A comparison across rows indicates that it is extremely expensive to support HMOs in counties inhabited by the final $10 \%$ of Medicare beneficiaries. To support a given number of HMOs for an additional $10 \%$ of enrollees in most cases requires an increment of less than $\$ 60$; however, for the last $10 \%$ of beneficiaries, it requires a payment increment of roughly $\$ 260$.

One might be concerned that there are certain counties in which it is extremely difficult to support HMOs in this program, and the history of nonparticipation in these counties affects the estimates for other counties. As a test of robustness, we re-estimated the models of this paper excluding the $20 \%$ of counties with the fewest Medicare beneficiaries. The results, not reported here but available upon request, are consistent with those for the sample used in this paper and confirm that the counties with the smallest population of Medicare beneficiaries tend to be those requiring the largest payment to support HMOs in $\mathrm{M}+\mathrm{C}$.

\section{EXTENSIONS}

In this section, we describe two extensions to this work in which we consider additional outcomes of interest: the existence of any (as opposed to the exact number) of HMOs participating in $\mathrm{M}+\mathrm{C}$ in the county, and the $\mathrm{HMO}$ market penetration rate.

First, we estimate a probit model in which the dependent variable is an indicator variable that equals one if there are any active $\mathrm{M}+\mathrm{C}$ HMOs in the county; the set of independent variables is the same as in the ordered probit regression. Table XII, which presents these results, indicates that a $\$ 100$ increase in CMS payment was associated with a $5 \%$ increase in the probability of at least one active HMO in the county prior to when the BBA took effect, and an $11 \%$ increase in that probability after the BBA took effect. A comparison of Tables VI and XII confirms the common-sense prediction that variables that increase the number of $\mathrm{HMOs}$ active in $\mathrm{M}+\mathrm{C}$ also increase the probability that any HMOs are active in $\mathrm{M}+\mathrm{C}$. For example, the number of general practitioners and the median rent in the county, and the number of Medicare beneficiaries in all surrounding counties are positively correlated with $\mathrm{HMO}$ participation, while the number of RNs, per capita income, and the poverty rate among the elderly are negatively correlated with $\mathrm{HMO}$ participation.

As a second extension, we estimate models in which HMO market penetration rate is the outcome of interest. The regressions using market 
TABLE XII.

PROBIT REGRESSION

DEPENDENT VARIABLE: INDICATOR VARIABLE FOR

WHETHER ANY HMO PARTICIPATING IN

MEDICARE+CHOICE IN COUNTY

\begin{tabular}{|c|c|c|}
\hline Variable & $\begin{array}{l}\text { Change in } \\
\text { Probability }\end{array}$ & Z Score \\
\hline \multicolumn{3}{|l|}{ Payment } \\
\hline CMS Payment & 0.0005 & 3.53 \\
\hline CMS Payment $*$ Indicator for $1998-2001$ & 0.0006 & 5.67 \\
\hline \multicolumn{3}{|l|}{ Indicator Variables for Year } \\
\hline 1994 & 0.0275 & 3.93 \\
\hline 1995 & 0.0596 & 8.60 \\
\hline 1996 & 0.0719 & 10.99 \\
\hline 1997 & 0.0747 & 10.41 \\
\hline 1998 & -0.1755 & -2.55 \\
\hline 1999 & -0.1961 & -2.71 \\
\hline 2000 & -0.3131 & -3.59 \\
\hline 2001 & -0.5904 & -05.17 \\
\hline \multicolumn{3}{|l|}{ Variables Affecting Average Variable Costs } \\
\hline Average Medicare Part A Costs & 0.000008 & 0.38 \\
\hline Average Medicare Part B Costs & -0.00002 & -0.69 \\
\hline Number of General Practitioners & 0.0007 & 4.60 \\
\hline Number of Registered Nurses & -0.00002 & -2.02 \\
\hline Number of Hospitals & 0.0007 & 0.41 \\
\hline Median Rent & 0.0004 & 4.85 \\
\hline Population Density & -0.000003 & -2.18 \\
\hline Percent Population in Urban Areas & -0.00009 & -0.35 \\
\hline \multicolumn{3}{|l|}{ Measures of the Size of the Market } \\
\hline Number of Medicare Beneficiaries & 0.000001 & 2.63 \\
\hline Percent Growth in Medicare Beneficiaries & 0.0029 & 0.13 \\
\hline \multicolumn{3}{|l|}{ Variables Affecting Fixed Costs of Entry } \\
\hline Number of HMOs in County in 1980 & 0.0078 & 0.82 \\
\hline Percent Workforce in Manufacturing & -0.0006 & -0.93 \\
\hline Percent Workforce White Collar & 0.0003 & 0.25 \\
\hline $\begin{array}{l}\text { Number of Medicare Beneficiaries } \\
\text { in All Adjacent Counties }\end{array}$ & 0.000004 & 5.44 \\
\hline $\begin{array}{l}\text { Percent Growth in Medicare Beneficiaries } \\
\text { in All Adjacent Counties }\end{array}$ & 0.1099 & 3.53 \\
\hline \multicolumn{3}{|l|}{ Variables Affecting the Probability of Enrollment } \\
\hline Per Capita Income & -0.000008 & -4.35 \\
\hline Poverty Rate Among Elderly & -3.88 & -3.07 \\
\hline Percent of Adults with High School Diploma & 0.0030 & 2.74 \\
\hline Percent of Adults with College Degree & -0.0013 & -0.94 \\
\hline Number of Observations & 27,666 & \\
\hline Log Likelihood & $-8,094.17$ & \\
\hline
\end{tabular}

Notes: Z Scores reflect cluster-corrections of standard errors by county.

Coefficients on indicator variables for missing values are omitted.

Regression is weighted by Medicare population of county. 
TABLE XIII.

\section{ORDINARY LEAST SQUARES REGRESSION \\ DEPENDENT VARIABLE: PERCENT OF MEDICARE \\ ELIGIBLES ENROLLED IN M+C HMO \\ (LOGIT TRANSFORMED)}

\begin{tabular}{|c|c|c|}
\hline Variable & Coefficient & T-Statistic \\
\hline \multicolumn{3}{|l|}{ Payment } \\
\hline CMS Payment & 0.0093 & 9.20 \\
\hline CMS Payment $*$ Indicator for 1998-2001 & 0.0022 & 7.93 \\
\hline \multicolumn{3}{|l|}{ Indicator Variables for Year } \\
\hline 1998 & -1.01 & -7.42 \\
\hline 1999 & -1.39 & -8.47 \\
\hline 2000 & -1.43 & -8.74 \\
\hline 2001 & -2.12 & -10.61 \\
\hline \multicolumn{3}{|l|}{ Variables Affecting Average Variable Costs } \\
\hline Average Medicare Part A Costs & -0.0001 & -0.29 \\
\hline Average Medicare Part B Costs & -0.0012 & -3.74 \\
\hline Number of General Practitioners & -0.0003 & -0.38 \\
\hline Number of Registered Nurses & -0.00004 & -0.77 \\
\hline Number of Hospitals & 0.009 & 0.78 \\
\hline Median Rent & 0.0008 & 1.07 \\
\hline Population Density & -0.00003 & -2.61 \\
\hline Percent Population in Urban Areas & 0.0106 & 3.74 \\
\hline \multicolumn{3}{|l|}{ Measures of the Size of the Market } \\
\hline Number of Medicare Beneficiaries & -0.0000009 & -0.03 \\
\hline Percent Growth in Medicare Beneficiaries & -0.042 & -0.16 \\
\hline \multicolumn{3}{|l|}{ Variables Affecting Fixed Costs of Entry } \\
\hline Number of HMOs in County in 1980 & 0.152 & 1.83 \\
\hline Percent Workforce in Manufacturing & -0.019 & -2.81 \\
\hline Percent Workforce White Collar & 0.0686 & 4.65 \\
\hline $\begin{array}{l}\text { Number of Medicare Beneficiaries } \\
\text { in All Adjacent Counties }\end{array}$ & 0.000001 & 3.32 \\
\hline $\begin{array}{l}\text { Percent Growth in Medicare Beneficiaries } \\
\text { in All Adjacent Counties }\end{array}$ & 1.284 & 3.58 \\
\hline \multicolumn{3}{|l|}{ Variables Affecting the Probability of Enrollment } \\
\hline Per Capita Income & -0.00001 & -0.68 \\
\hline Poverty Rate Among Elderly & -9.42 & -7.18 \\
\hline Percent of Adults with High School Diploma & -0.0121 & -0.96 \\
\hline Percent of Adults with College Degree & -0.0494 & -3.23 \\
\hline Number of Observations & 15,369 & \\
\hline$R$-squared & 0.56 & \\
\hline
\end{tabular}

Notes: $t$-statistics reflect cluster-corrections of standard errors by county.

Coefficients on indicator variables for missing values are omitted.

Regression is weighted by Medicare population of county.

penetration as an outcome of interest use fewer years of data than the models presented earlier in this paper because CMS has only released county market penetration rates in $\mathrm{M}+\mathrm{C}$ since 1997 . We use the logit transformation so the dependent variable is of the form $\ln \left(\frac{P}{1-P}\right)$ where 
$P$ represents the proportion of Medicare eligibles enrolled in a $\mathrm{M}+\mathrm{C}$ HMO. ${ }^{31}$

Results of the market penetration regressions appear in Table XIII. The coefficients on both CMS payment and CMS payment interacted with BBA regime are positive and statistically significant at a $1 \%$ level, confirming that, controlling for costs, a higher CMS payment is associated with greater market penetration by HMOs into Medicare. Based on these results, HMO participation is quite elastic to CMS payment: the elasticity is 3.93 before the BBA and 4.94 after the BBA.

The market penetration results in Table XIII are similar to the ordered probit regression results in Table VI in that the number of Medicare beneficiaries residing in all adjacent counties, the percent of the county population living in an urban area, and a lower poverty rate among the elderly are associated with both a larger number of HMOs in $\mathrm{M}+\mathrm{C}$ and a greater penetration rate by HMOs into Medicare. ${ }^{32}$

\section{CONCLUSION}

This paper estimates the CMS payments necessary to support the participation of a given number of HMOs in Medicare managed care per county market. Ordered probit estimates suggest that in order to support one Medicare HMO in half of US counties in the year 2001, CMS would have to pay $\$ 581$ per average enrollee per month in the marginal county. Analogously, to support one Medicare HMO in every county in the US in the year 2001, CMS would need to pay $\$ 877$ per enrollee per month in the marginal county. In contrast, CMS payments for 2001 averaged $\$ 498.82$ and ranged from $\$ 475.00$ to $\$ 833.55$.

It has been found that when several $\mathrm{M}+\mathrm{C}$ HMOs are active in a county, competition among the HMOs generates additional services at lower cost for enrollees; if CMS desires the participation of multiple HMOs in county markets, our estimates suggest that even greater payments are required. Conditional on two HMOs already participating in $\mathrm{M}+\mathrm{C}$, roughly an extra $\$ 60$ per enrollee per month is necessary to support each additional HMO.

We also find that, in 2001, $81.75 \%$ of all counties in the contiguous 48 United States received less than the estimated amount necessary to

31. To avoid missing values after the logit transformation, penetration rates of zero were recoded to 0.0001 .

32. In market penetration regressions in which we control for county-fixed effects (not shown in table form), the effect of payment on market penetration is weakened. This is not surprising, because fixed effects remove important variation in payment across counties. After the BBA took effect, payments in most counties increased only 2-3\% per year, so little variation in payments remains after controlling for county-fixed effects. 
support an HMO in this market. Compared to counties that received more than the estimated threshold for HMO participation, the counties receiving an insufficient payment are on average more rural and less populated with citizens who are less wealthy and less educated. The relative disadvantage of rural and unpopulated counties persists 3 years after the BBA of 1997, designed to eliminate such disparities, took effect. We find that a large incremental payment would be required to include the final $10 \%$ of counties among those supporting an $\mathrm{HMO}$ in $\mathrm{M}+\mathrm{C}$.

While in the year 2001 only $18.25 \%$ of counties in the contiguous 48 United States received a CMS payment greater than what was necessary to support a single HMO in the Medicare managed care market, these counties were home to $66.8 \%$ of all Medicare beneficiaries.

The exits of HMOs in some counties, combined with the healthy participation of HMOs and rich set of benefits offered in other counties, suggests that when setting prices for this program, the Federal government underestimated the costs of HMOs in many counties while overestimating their costs in others. The root problem with the fiat method of setting payments is a lack of information; even with the growth of information technology, the Federal government does not have the resources to track changes in costs in every local health care market in the US in order to accurately set payments in this program. Moreover, it is difficult to predict how the costs of $\mathrm{M}+\mathrm{C}$ enrollees may differ from those for the overall Medicare population. The lack of information about future changes in costs in local health care markets is also the reason that this paper does not predict how much needs to be paid next year to achieve the participation of various numbers of HMOs.

In 2003, Congress acknowledged that the fiat system of payment was flawed when it passed the Medicare Prescription Drug, Improvement, and Modernization Act. This law requires that CMS implement in 2006 a system of competitive bids to set payments in this program; providers will bid for the right to enroll Medicare beneficiaries. If the process is properly structured, the bids will reveal the information CMS currently lacks: providers' private information about the costs of health care delivery in local areas.

\section{REFERENCES}

Abraham, J., A. Arora, M. Gaynor, and D. Wholey, 2000. “Enter at Your Own Risk: HMO Participation and Enrollment in the Medicare Risk Market," Economic Inquiry, 38(3), 385-401.

Adamache, K.W. and L.F. Rossiter, 1986. "The Entry of HMOs Into the Medicare Market: Implications for TEFRA's Mandat," Inquiry, 23, 349-64.

Booske, B., J. Lynch, and G. Riley, 2002. "Impact of Medicare Managed Care Market Withdrawal on Beneficiaries," Health Care Financing Review, 24(1), 95-115. 
Bresnahan, T.F., and P.C. Reiss, 1987. "Do Entry Conditions Vary Across Markets?" Brookings Papers on Economic Activity, 1987(3), 833-881.

— - and — 1991a. "Empirical Models of Discrete Games," Journal of Econometrics, $48(1 / 2), 57-81$.

— Political Economy, 99(5), 977-1009.

Brown, R.S. and M.R. Gold, 1999. "What Drives Medicare Managed Care Growth?" Health Affairs, 18(6), 140-49.

Cameron, A.C., and P.K. Trivedi, 1998. Regression Analysis of Count Data, New York: Cambridge University Press.

Dowd, B., R. Coulam, and R. Feldman, 2000. "A Tale of Four Cities: Medicare Reform and Competitive Pricing," Health Affairs, 19(5), 9-56.

Efron, B. and R.J. Tibshirani, 1993. An Introduction to the Bootstrap, New York: Chapman \& Hall.

General Accounting Office, 1997. "Medicare: Fewer and Lower Cost Beneficiaries with Chronic Conditions Enroll in HMOs," Report 97-160, Washington, DC: United States General Accounting Office.

_ 1997. "Medicare Managed Care: HMO Rates, Other Factors Create Uneven Availability of Benefits," Report 97-113, Washington, DC: United States General Accounting Office.

_ 2000. “Medicare+Choice: Payments Exceed Cost of Fee-for-Service Benefits, Adding Billions to Spending," Report 00-161, Washington, DC: United States General Accounting Office.

— , 2001. "Medicare+Choice: Recent Payment Increases Had Little Effect on Benefits or Plan Availability in 200." Report 02-202, Washington, DC: United States General Accounting Office.

Glied, S., 2000. "Managed Care" in Anthony J. Culyer and Joseph P. Newhouse, eds., Handbook of Health Economics, Volume 1A, New York: Elsevier/North-Holland.

Health Care Financing Administration, 1999. "Protecting Medicare Beneficiaries After HMOs Withdraw," HCFA Fact Sheet, July 15, Washington, DC: Department of Health \& Human Services.

—_, 2000. "Protecting Medicare Beneficiaries After Medicare+Choice Organizations Withdraw," HCFA Fact Sheet, Washington, DC: Department of Health \& Human Services.

— - 1990-2001. Medicare Managed Care Contract Reports. Washington, DC: Department of Health \& Human Services.

Laschober, M.A., P. Neuman, M.S. Kitchman, L. Meyer, and M. Langwell, 1999. “Medicare HMO Withdrawals: What Happens to Beneficiaries?" Health Affairs, 18(6), 150-57.

Liu, S., 2002. "Analyzing Geographic Differences in the Medicare HMO Market," Unpublished manuscript University of California at Irvine.

Marshall, A., 1920. Principles of Economics. Eighth edition, Philadelphia, PA: Porcupine Press.

Pakes, A. and P. McGuire, 1994. “Computing Markov Perfect Nash Equilibrium: Numerical Implications of a Dynamic Differentiated Product Model," Rand Journal of Economics, 25(4), 555-589.

Pai, C.-W. and D.G. Clement, 1999. "Recent Determinants of New Entry of HMOs into a Medicare Risk Contract: A Diversification Approach," Inquiry, 36(1), 78-89.

Penrod, J.D. and T.D. McBride, 2001. "Geographic Variation in Determinants of Medicare Managed Care Enrollment," Health Services Research, 36(4), 733-750.

Physician Payment Review Commission, 1996. Annual Report to Congress, Washington, DC: Physician Payment Review Commission. 
Pizer, S.D. and A.B. Frakt, 2002. "Payment Policy and Competition in the Medicare+Choice Program," Health Care Financing Review, 24(1), 83-94.

Porell, F.W. and S.S. Wallack, 1990. "Medicare Risk Contracting: Determinants of Market Entry," Health Care Financing Review, 12(2), 75-85.

PR Newswire, 2002. "Remarks by the President to Coalition for Medicare Choices." May 17.

2003. "Seniors Rally in Support of Medicare+Choice; AAHP Releases Poll Showing Seniors in Medicare Overwhelmingly Support Choice." May 14.

Serrato, C., R.S. Brown, and J. Bergeron, 1995. "Why Do So Few HMOs Offer Medicare Risk Plans in Rural Areas?" Health Care Financing Review, 17(1), 85-97.

Sutton, J., 1991. Sunk Costs and Market Structure, Cambridge, MA: MIT Press. 